Available online on 15.01 .2020 at http://jddtonline.info
Open Access to Pharmaceutical and Medical Research
unrestricted non-commercial use, provided the original work is properly cited

Open ${ }_{\text {Access }}$

Review Article

\title{
The Use of Natural Products in the Management of Diabetes: The Current Trends
}

\section{*Adedapo AA and Ogunmiluyi IO}

Department of Veterinary Pharmacology and Toxicology, University of Ibadan, Ibadan, Nigeria

\section{ABSTRACT}

Natural products have played and continue to play a great role in the management of different diseases. Natural products are usually believed to be safer, cheaper, easily available and sometimes more efficacious than purely synthetic drugs. Diabetes mellitus is a major health problem in the world. There is no cure for diabetes. With the increase in a number of newer drugs for diabetes, there is the possibility of a wide range of side effects that vary from one drug to another. It is, therefore, essential to practice effective methods of the treatment and management of diabetes. Hence, the need to explore antidiabetic drugs of natural origin with minimal side effects is highly essential. This review provides a scientific perspective on the usage and research of natural traditional remedies in the management of diabetes. The aim of the present review is to provide a comprehensive and concise overview of the previously reported clinical trials of antioxidative natural products in the management of diabetes.
\end{abstract}

Keywords: Diabetes, Natural products, Hyperglycemia, Diabetic complications,

Article Info: Received 14 Oct 2019; Review Completed 22 Dec 2019; $\quad$ Accepted 30 Dec 2019; Available online 15 Jan 2020

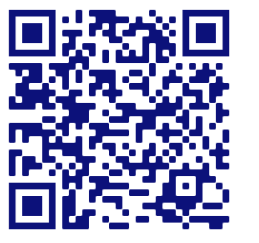

Cite this article as:

Adedapo AA, Ogunmiluyi IO, The Use of Natural Products in the Management of Diabetes: The Current Trends, Journal of Drug Delivery and Therapeutics. 2020; 10(1):153-162 http://dx.doi.org/10.22270/jddt.v10i1.3839

*Address for Correspondence:

Adedapo AA, Department of Veterinary Pharmacology and Toxicology, University of Ibadan, Ibadan, Nigeria. Email: adedapo2a@gmail.com; +2348162746222

\section{INTRODUCTION}

Diabetes mellitus (DM) is a common metabolic disorder that involves a defect in insulin secretion, its action, or both [1]. Deficiency of insulin results in chronic hyperglycemia (increased fasting and postprandial blood sugar (glucose) levels) and defect in the metabolism of protein, fat and carbohydrate [2].

Diabetes mellitus is classified based on its cause and clinical signs and symptoms. In general, diabetes is classified into 4 types, which include type 1 diabetes mellitus or non-insulin dependent diabetes mellitus, type 2 diabetes or insulin dependent diabetes mellitus, gestational diabetes, and other specific types. Non-insulin dependent diabetes mellitus is the major type of diabetes in younger people. Although the prevalence of type 1 diabetes is increasing all over the world, it still accounts for a minority. Children of earlier age groups are more prone to type 1 diabetes mellitus [3].

Diabetes is a complex disease that can result in different complications; it demands a multifarious therapeutic approach. Drug therapy is provided to patients whose cells do not respond to insulin whereas insulin deficiency is managed by insulin injections in patients who show a total lack of insulin [2]. 
Increase in Insulin Secretion

- Sulfonylureas

- Meglitinides

- Glucagon-like peptide-1 receptor agonists

- Dipeptide pepdidase-4 inhibitors

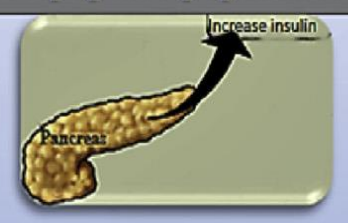

\section{具}
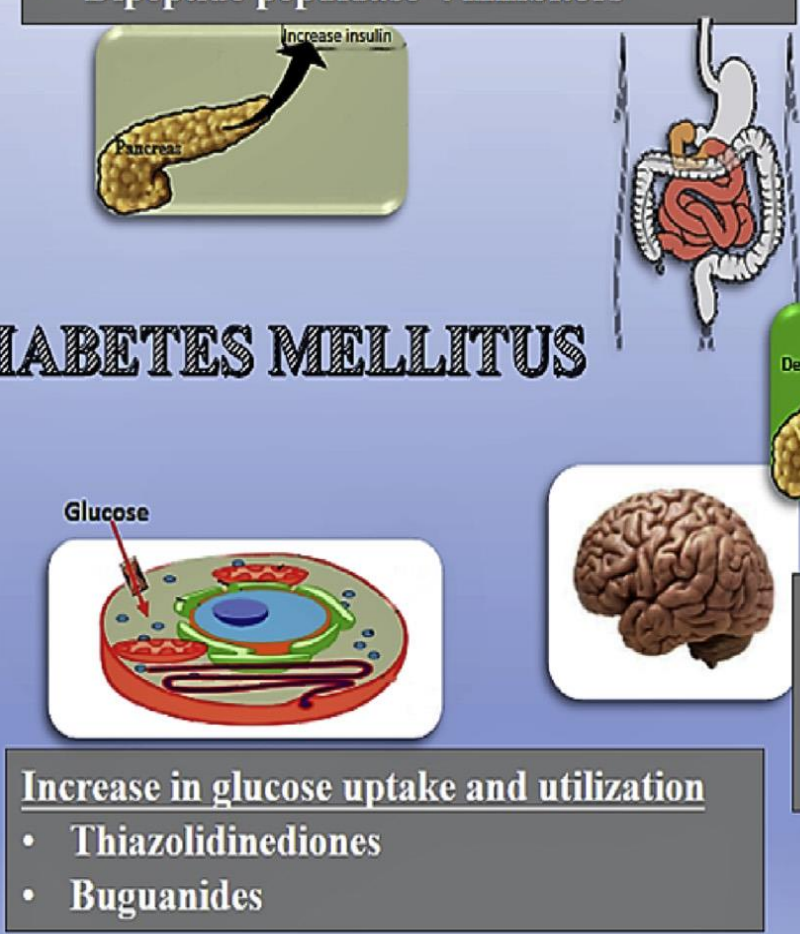

\section{Decrease glucose absorption from} GIT

- $\alpha$-glucosidase inhibitor

- Dipeptide pepdidase-4 inhibitors

\section{Decrease in glucagon secretion}

- Amylin analogue

- a-glucosidase inhibitor

- Dipeptide pepdidase-4 inhibitors

\section{Decrease appetite}

- Amylin analogue

- Dipeptide pepdidase-4

inhibitors

\section{MANAGEMENT OF DIABETES MELLITUS USING NATURAL PRODUCTS}

\section{Need for natural remedies}

Defects in insulin secretion are the one of the main causes that leads to Diabetes Mellitus. Recently, numerous botanical herbs have demonstrated antidiabetic potential through regulation of insulin secretion. As the long-term use of conventional secretagogues such as glibenclamide in diabetes patients tend to cause damage of b-cells due to overstimulation of pancreatic islet,

Different categories of antidiabetic medications are there in the market for the remedial action, which includes insulin analogues, sulphonylureas, biguanides, dipeptidyl peptidase4 inhibitors, thiazolidiones, a-glucosidase inhibitors, etc, where the mechanism of counteracting this increased glucose level is different for different categories. However, long term treatment and side effect of the available hypoglycemic medications leading towards huge demand for efficacious, decreased side effects and affordable agents for the treatment of diabetic condition.

Most of the studies on herbal and natural products have reported for the better anti-diabetic effects with lower cost and fewer side effects than synthetic drugs. Most antidiabetic herbs can improve $\beta$-cell function and increase the secretion of insulin from the islets of Langerhans, which have high antioxidant power.

\section{Karela (Momordica charantia Linn)}

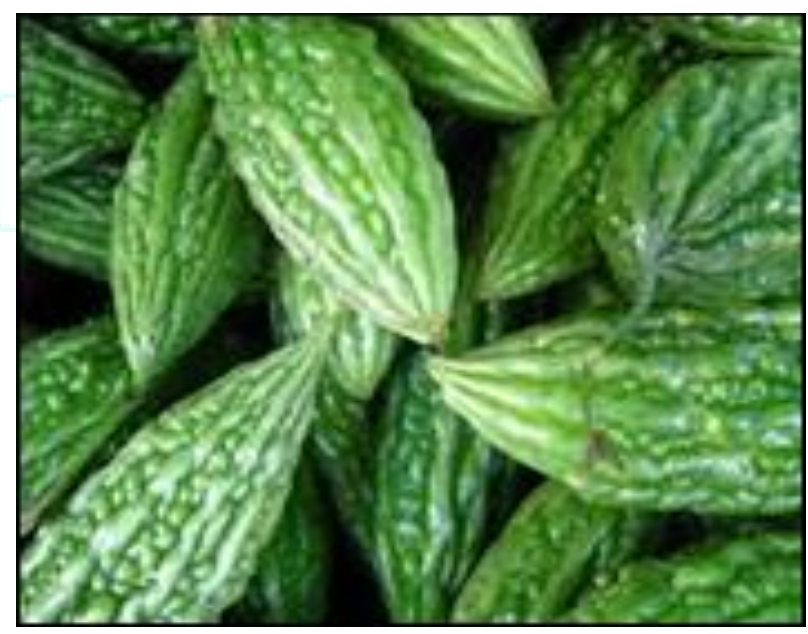

It is very popular for its anti-diabetic properties. It's also rich in micronutrients, which are required for prevention of complications of diabetes. Bitter melon, also known as balsam pear, is a tropical vegetable widely cultivated in Asia, Africa and South America, and has been used extensively in folk medicine as a remedy for diabetes. The blood sugar lowering action of the fresh juice or extract of the unripe fruit has been clearly established in both experimental and clinical studies ${ }^{[4]}$.

Bitter melon is composed of several compounds with confirmed anti-diabetic properties. Charantin, extracted by alcohol, is a hypoglycaemic agent composed of mixed 
steroids that is more potent than the drug tolbutamide, which is often used in the treatment of diabetes. Momordica also contains an insulin-like polypeptide, polypeptide-P, which lowers blood sugar levels in type 1 diabetic patient. The oral administration of 50-60 $\mathrm{ml}$ of the juice has shown good results in clinical trials [5] .

Excessively high doses of bitter melon juice can cause abdominal pain and diarrhea. Small children or anyone with hypoglycemia should not take bitter melon, since this herb could theoretically trigger or worsen low blood sugar, or hypoglycemia. Furthermore, diabetics taking hypoglycemic drugs (such as chlorpropamide, glyburide, or phenformin) or insulin should use bitter melon with caution, as it may potentiate the effectiveness of the drugs, leading to severe hypoglycemia $[4,6]$.

\section{Gurmar (Gymnema sylvestre Linn)}

Gymnema assists the pancreas in the production of insulin in Type 2 diabetes. Gymnema also improves the ability of insulin to lower blood sugar in both Type 1 and Type 2 diabetes. It decreases cravings for sweet. This herb can be an excellent substitute for oral blood sugar-lowering drugs in Type 2 diabetes. Some people take $500 \mathrm{mg}$ per day of gymnema extract [7].

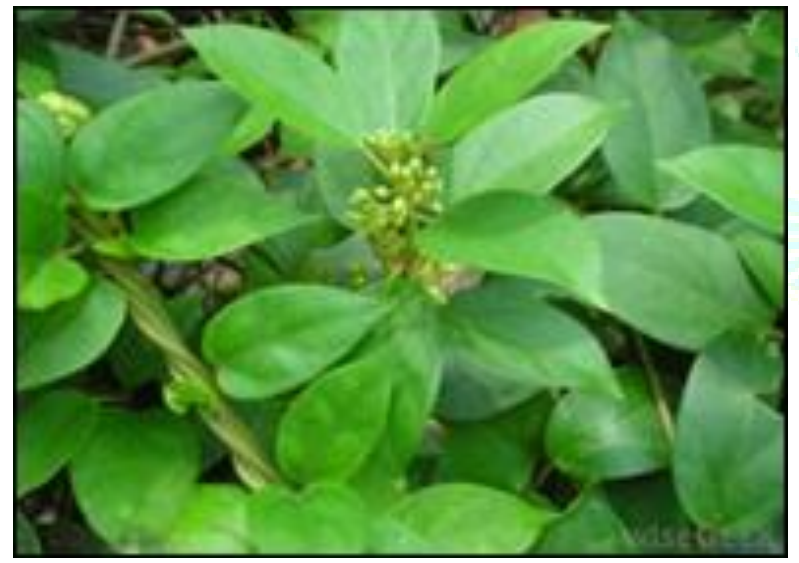

Pyaz/Lehsan (Allium cepa Linn and Allium sativum Linn)

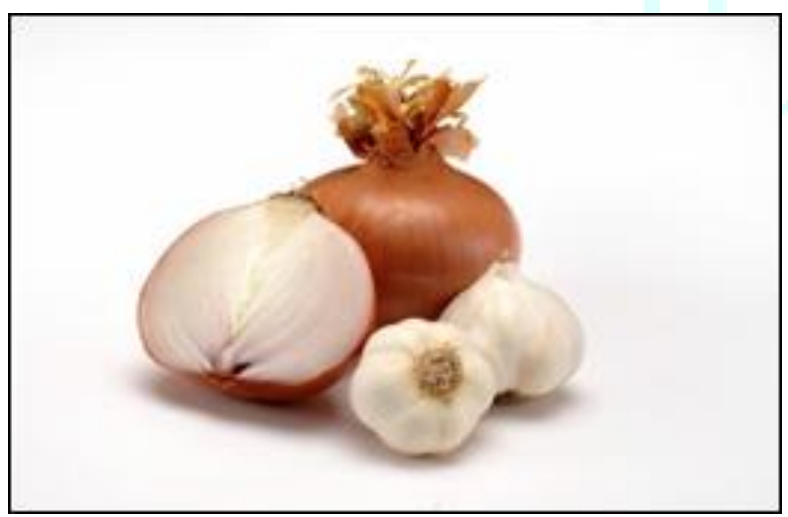

Onion and garlic have significant blood sugar lowering action. The principal active ingredients are believed to be allyl propyl disulphide (APDS) and diallyl disulphide oxide (allicin), although other constitutents such as flavonoids may play a role as well.

Experimental and clinical evidence suggests that APDS lowers glucose levels by competing with insulin for insulininactivating sites in the liver. This results in an increase of free insulin. APDS administered in doses of $125 \mathrm{mg} / \mathrm{kg}$ to fasting humans was found to cause a marked fall in blood glucose levels and an increase in serum insulin. Allicin doses of $100 \mathrm{mg} / \mathrm{kg}$ produced a similar effect $[7,8]$.
Onion extract was found to reduce blood sugar levels during oral and intravenous glucose tolerance. The effect improved as the dosage was increased; however, beneficial effects were observed even for low levels that used in the diet e.g. 25 to 200 grams. The effects were similar in both raw and boiled onion extracts. Onions affect the hepatic metabolism of glucose and/or increase the release of insulin and/or prevent insulin's destruction [4]

The additional benefit of the use of garlic and onions are their beneficial cardiovascular effects. They are found to lower lipid levels, inhibit platelet aggregation and are antihypertensive. So, liberal use of onion and garlic are recommended for diabetic patients.

\section{Methi (Trigonella foenum-graecum Linn)}

The active ingredient for the antidiabetic properties of fenugreek is in the defatted portion of the seed that contains the alkaloid trogonelline, nicotinic acid and coumarin.

Fenugreek may help improve blood glucose levels in people with both Type 1 and Type 2 diabetes, according to several studies. In addition, this herbal diabetic treatment may also help improve blood cholesterol and triglyceride levels [4].

\section{Darchini (Cinnamon zylanicum Linn)}

Cinnamon comes from the inner bark of a tropical evergreen tree and has insulin-like properties. This herbal diabetic treatment can help lower blood glucose levels as well as cholesterol and triglycerides, and some studies suggest that cinnamon can help boost antioxidants in the body and may help reduce metabolic syndrome $[9,10]$.

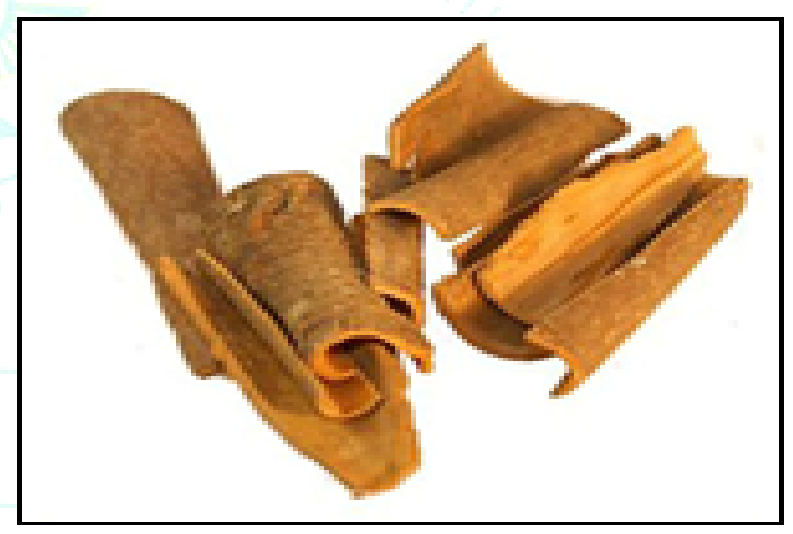

Jamun (Eugenia Jambolana Linn)

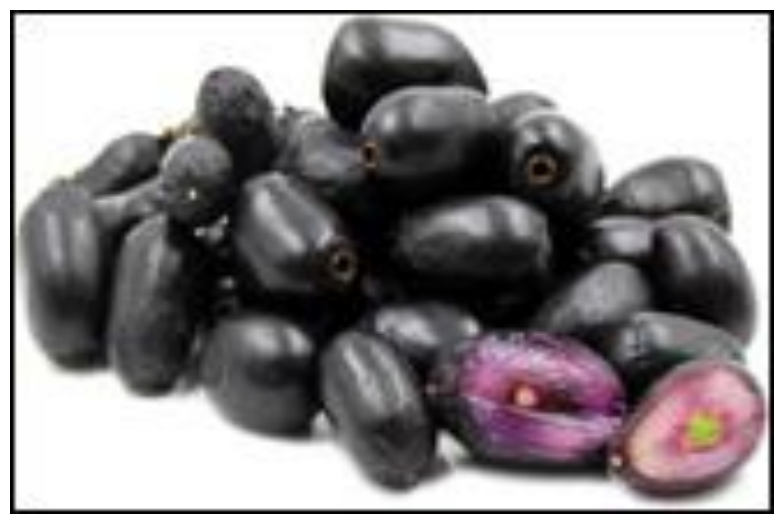

The fruit and seeds of the Jambul tree have long been used in Eastern traditional medicine. The extract of the jamun pulp showed hypoglycemic activity within $30 \mathrm{~min}$ of administration, while the seeds of the same fruit require 24 hrs. There was increase in serum insulin level and the extract also inhibited insulinase activity from liver and kidney [7]. 


\section{Ghekwar (Aloe Vera)}

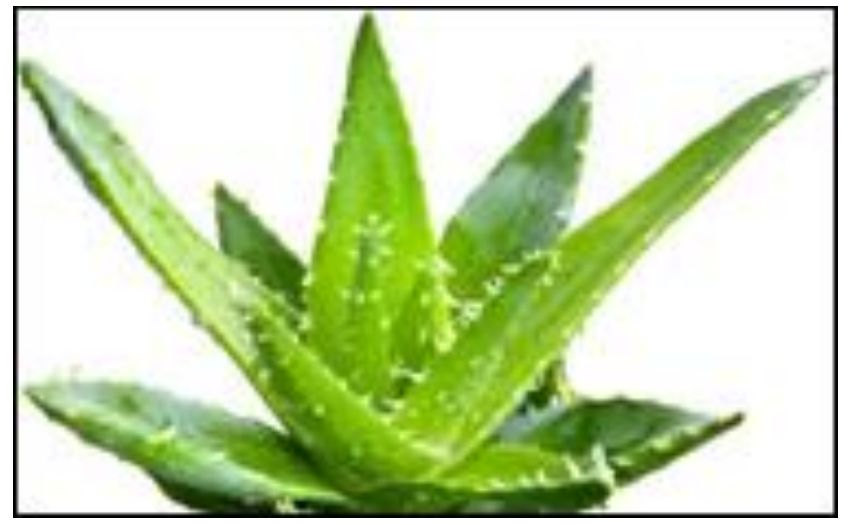

Aloe vera is a popular houseplant, has a long history as a multipurpose folk remedy. The plant can be separated into two basic products: gel and latex. Aloe Vera gel is the leaf pulp or mucilage, aloe latex, commonly referred to as "aloe juice," is a bitter yellow exudate from the pericyclic tubules just beneath the outer skin of the leaves. Extracts of aloe gum effectively increases glucose tolerance in both normal and diabetics [8].

\section{Mango leaves (Mangifera indica Linn)}

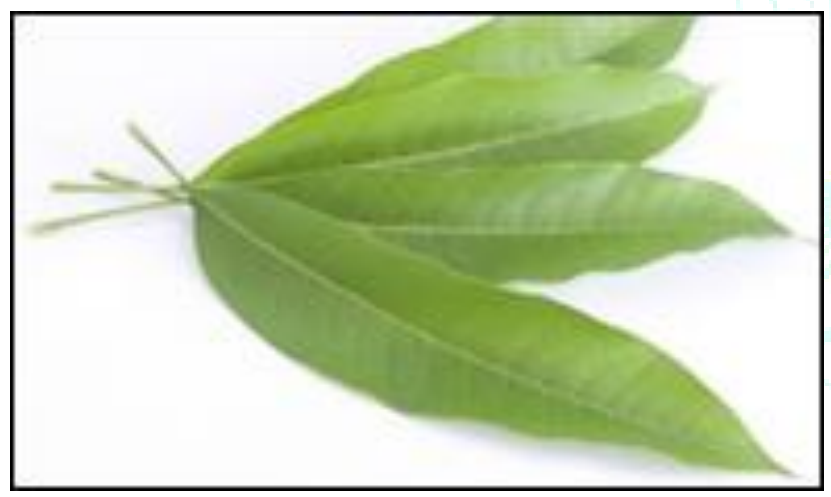

Effect of leaves of Mangifera indica on Diabetic Nephropathy is good. It significantly inhibited glomerula's extra cellular matrix expansion and accumulation and transforming growth factor- beta -1 over expansion in glomeruli of Diabetic nephropathic patients. Mangiferin has an immunestimulating effect on both cellular and hormonal immunity link. Mangiferin is a normal metabolite also to be found in mango leaves [4].

Pharmacokinetics of Mangiferin in the blood after oral administration: A small amount of free Mangiferin is observed in the blood plasma after single use of Mangiferin at dose range between $50 \mathrm{mg} / \mathrm{kg}$ and $1000 \mathrm{mg} / \mathrm{kg}$. Plasma level of Mangiferin is not over $0.05 \mu \mathrm{g} / \mathrm{ml}$ over 24-hour follow-up. Mangiferin metabolite is not detected in the blood within 24 hours after oral administration. Excretion of free Mangiferin in the urine is not over $0.1 \%$ within 24 hours [4].

\section{Antioxidative natural products in clinical trials of diabetes}

Aloe vera Inner Leaf Gel Powder: Aloe vera inner leaf gel powders (UP780 and AC952) were used in patients with impaired fasting glucose or impaired glucose tolerance during an 8-week period in a double-blind, placebo controlled study [11]. It was reported that both AC952 and UP780 could markedly reduce fasting glucose and improve glucose tolerance and lipoprotein levels in the plasma [11]. However, the reduction of oxidative stress marker urinary F2-isoprostanes was solely noted for UP780 compared with the placebo.
Black Tea: Mahmoud et al. tested the effects of black tea ingestion on the secretion of inflammatory cytokines and metabolic biomarkers in 30 patients with T2DM [12]. The results indicated that treatment with black tea at 200 or 600 $\mathrm{ml}$ per day, for 12 weeks, resulted in significantly decreased glycosylated hemoglobin levels and decreased total serum cholesterol levels and the markers of oxidative stress. Furthermore, the supplementation of black tea could inhibit the inflammatory response including an increase in regulatory $\mathrm{T}$ cell secretion and a decrease in the production of proinflammatory cells [12].

Chamomile Tea: A single-blind randomized controlled clinical trial was conducted on 64 patients with T2DM to evaluate the effect of the antioxidative natural product chamomile tea [13]. Chamomile tea, at $3 \mathrm{~g} / 150 \mathrm{ml}, 3$ times per day, was administered for 8 weeks and was shown to decrease the concentration of serum glycosylated hemoglobin, MDA, insulin, and improved insulin resistance [13]. Additionally, chamomile tea increased total antioxidant capacity of SOD, GSH, and CAT by $6.81 \%, 26.16 \%, 36.71 \%$, and $45.06 \%$, respectively [13]. This trial indicates that intake of chamomile tea could benefit glycemic control and antioxidant status in patients with T2DM.

Nigella sativa: The long-term effect of Nigella sativa on T2DM patients taking standard hypoglycemic drugs was evaluated [14]. The 1-year treatment with Nigella sativa led to elevated serum total antioxidant activity and the levels of GSH and SOD, as compared with the non-Nigella sativa treated group [14]. Additionally, a significant decrease in fasting blood glucose and glycosylated hemoglobin and an improvement in insulin resistance and $\beta$-cell activity were observed in the Nigella sativa-treated group [14]. These findings suggest the potential of Nigella sativa supplementation as an alternative method to benefit patients with T2DM.

Phyllanthus emblica Extract (PEE): PEE has a rich source of vitamin C, which is an important antioxidant that prevents platelet aggregation in healthy individuals and patients with coronary artery disease [15]. The 10-day treatment with PEE, at a dose of $500 \mathrm{mg}$ twice per day, was well tolerated in patients with T2DM, exhibited inhibitory effect on platelet aggregation, and prolonged the bleeding and clotting time, the effects of which were similar to those of the daily treatment with $75 \mathrm{mg}$ clopidogrel or ecosprin [15].

Aged Garlic Extract: Aged garlic extract has antioxidative and antihyperglycemic effects $[16,17,18]$. Supplementation of aged garlic extract in the diet reduced oxidative stress and improved endothelial dysfunction in humans [19, 20]. In a double-blind randomized placebo-controlled crossover pilot trial in patients with T2DM and high cardiovascular risk ( $30 \%$ risk of a cardiovascular event in the next 10 years), the 4-week treatment with aged garlic extract, administered daily at $1200 \mathrm{mg}$, did not produce significant beneficial effects on body weight, blood pressure, lipids, insulin resistance, and biomarkers of endothelial dysfunction, oxidative stress, and inflammation [21]. Although the authors indicated that the recruitment of patients with higher cardiovascular risk or the supplementation of aged garlic extract for a longer period would produce more pronounced effects [21]. There is need for further exploration on the mechanism, dose, and safety of this natural product in future studies.

Salvia miltiorrhiza Hydrophilic Extract (SMHE): A randomized controlled clinical study was conducted, using SMHE, to test the protective and antioxidative properties of the extract in diabetic patients with chronic heart disease [22]. SMHE was administrated at a dose of $5 \mathrm{~g}$, twice per day, 
to the patients for 60 days in addition to their antihyperglycemic therapies. The serum MDA level was decreased by SMHE on day 30. On day 60, the serum GSH, SOD, paraoxonase, and glutathione reductase were significantly increased by SMHE. The lipid levels were not altered by SMHE [22]. This study indicates that SMHE has antioxidative activity and attenuates oxidative stress in diabetic patients with chronic heart disease. Determination of serum biomarkers for cardiac injury, cardiac remodeling, and cardiac dysfunction would be helpful in order to know the cardiac protective effect of SMHE under the diabetic condition

\section{Antioxidative Role of Natural Products in DCM}

The antioxidative effect of natural products on the attenuation of DCM has been extensively investigated in recent years [23] showing promising outcomes.

Sulforaphane (SFN): In a STZ-induced mouse model of DM, treatment with SFN for either 3 months or 6 months significantly activated Nrf2 signaling and prevented DMinduced cardiac oxidative damage, inflammation, hypertrophy, fibrosis, and dysfunction [24]. Nrf2 played a crucial role in the protective effect of SFN, at least on HGinduced fibrotic response in cultured cardiomyocytes, since SFN lost this effect in the presence of Nrf2 siRNA [24] Similarly, in a mouse model of type 2 diabetes (T2DM), SFN was able to activate Nrf2 antioxidant signaling, the effect of which restored the oxidative stress induced inhibition of liver kinase $\mathrm{B} 1 / 5^{\prime}$ AMP-activated protein kinase (LKB1/AMPK) signaling pathway and prevented T2DMinduced lipotoxicity and cardiomyopathy [25]. The crucial role of Nrf2 in mediating the protection by SFN against DCM was further demonstrated by using Nrf2 knockout mice [26]. Moreover, metallothionein, a potent antioxidant [27], was identified to be a downstream target of Nrf2 and predominantly mediated SFN's protective effects on diabetic nephropathy [28] and DCM [26]. The effect of SFN has been tested in a double-blind clinical trial of T2DM, showing a significant improvement of insulin resistance [29]. In addition to the improvement of insulin resistance [29]. SFN has the advantage of ameliorating DCM and therefore has a good potential for the use in future clinical trials of DCM.

Curcumin: Curcumin was found to reduce myocardial capillary sclerosis [30]; attenuate cardiac tissue damage, myocardial cell hypertrophy, and apoptosis; reduce extracellular protein accumulation; and preserve left ventricular function [31,32,33] in the hearts of STZ-induced diabetic rats. Mechanistically, curcumin was found to increase HO-1 [33], catalase (CAT), superoxide dismutase (SOD), and GSH [30]. In addition, the ability to reduce the expression of the NOX subunits p22 phox, p47 phox, p67 phox, and gp91 phox could also account for curcumin's protective effects on DCM [31,32]. In HG-cultured neonatal rat cardiomyocytes, curcumin suppressed the expression of the NOX subunit Rac1 and reduced HG-induced oxidative stress, the effect of which inhibited the HG-induced apoptotic cell death [34]

Although curcumin was found to have antioxidative effects on DCM, the exact target through which curcumin exerted the functions remained unclear. Gene knockout and silencing approaches could aid the investigation of the exact mechanism of antioxidative function induced by curcumin.

Furthermore, curcumin exhibits a poor bioavailability in plasma and in target tissues, which may hinder its therapeutic efficacy [35]. Therefore, the improvement of the pharmacokinetics and the increase in the plasma concentration of curcumin are significant therapeutic targets in the application of curcumin for the treatment of DCM. Recently, C66, a curcumin derivative with much a higher bioavailability [35,36],(Wu, et al, 2016; Pan, et al, 2014), was found to activate Nrf2 and its downstream antioxidants in the kidneys and aortas of the STZ-induced diabetic mice [35, 37]. Nrf2 played a prominent role in the $\mathrm{C} 66$ protection against diabetic nephropathy, since C66 lost partial, but significant, protection against the DM-induced renal damage [35] in the Nrf2 knockout mice.

Icariin: Icariin was reported to inhibit mitochondrial oxidative stress and increase SOD activity in the hearts of the STZ-induced diabetic rats. Icariin reduced myocardial collagen deposition, inhibit ventricular hypertrophy, reverse the DM-induced body weight loss, and improve cardiac function [38]. These may indicate the efficiency of inhibiting mitochondrial ROS generation and increasing antioxidant capacity in ameliorating DCM. However, blood glucose levels were not indicated by this report, the result of which might be important to know whether the amelioration of DCM was caused by the icariin reduction of oxidative stress or by the amelioration of DM.

Flos puerariae (FPE): FPE was shown to inhibit gp91 phox and p47 phox, the two subunits of NOX in the hearts of STZinduced C57BL/6J diabetic mice [39]. Additionally, FPE inhibited the DM-induced ROS generation and enhanced the activity of SOD and glutathione peroxidase (GSH-Px) maintained myocardial structure, and attenuated DMinduced apoptotic cardiac cell death [39]. Thus, FPE had the capability to both inhibit NOX expression and upregulate the expression of antioxidants in the hearts of the diabetic mice. Despite the speculation of c-Jun N-terminal kinase and P38 mitogen-activated protein kinase to be the target of FPE further investigations are needed to elucidate the mechanism of this natural product in the amelioration of DCM.

Betanin: Betanin, extracted from natural pigments, was shown to have a protective effect against high fructose feedinduced diabetic cardiac fibrosis in Sprague-Dawley rats [40]. The DM-induced expression of the cardiac profibrotic factors transforming growth factor $\beta$ (TGF- $\beta$ ) 1 and connective tissue growth factor were significantly inhibited by betanin. The further mechanistic study revealed the efficacy of betanin in inhibiting the AGE/RAGE signaling, oxidative stress, and NF$\kappa \mathrm{B}$ under the diabetic condition.

Given that cardiac fibrosis is a hallmark of DCM and contributes to cardiac dysfunction, the effect of betanin on the inhibition of fibrotic signaling should attract attention for the future studies on DCM.

Chrysin: Chrysin was found to activate PPAR- $\gamma$; upregulate CAT, MnSOD, and GSH; inhibit AGE/RAGE signaling and oxidative stress; and attenuate apoptosis. These results provided evidence for PPAR- $\gamma$ activation in the potential management of DCM. However, more studies are needed to clarify the exact role of chrysin and other PPAR $-\gamma$ activators in ameliorating DCM.

Aralia taibaiensis (sAT): sAT, with antioxidative property $[41,42]$, is a traditional Chinese medicine that is frequently used in patients with DM [43]. It was recently reported to activate Nrf2 signaling and reduce $\mathrm{HG}$ and glucose oxidaseinduced apoptosis, ROS, and oxidative damage in cardiomyocytes [44]. Nrf2 was the key factor through which sAT exerted the protection, since the effects of sAT were markedly abolished in the presence of the Nrf2 siRNA.

Magnolia Plant Extracts (BL153 or 4-0-Methylhonokiol): BL153 showed beneficial effects on high-fat diet-induced 
cardiac [45] and aortic damage [46], via inhibition of oxidative stress. In addition, it has been shown that 4Omethylhonokiol (MH), a bioactive constituent of BL153, reduced high-fat diet- (HFD-) induced cardiac pathological changes, including increased heart weight and abnormal echocardiography parameters [47]. The observation of the enhanced Nrf2/HO-1 signaling in the hearts of the $\mathrm{MH}$ treated mice [47] could be responsible for the decreased oxidative stress by $\mathrm{MH}$. Both BL153 and MH had the capability to lower serum lipid level and improve insulin resistance in HFD animal models [25]. The effect of BL153 and MH should be tested in future studies on animal models of T1DM, since Nrf2 was shown to play a key role in protection against DCM in T1DM.

Abroma augusta L. Leaf: It was tested in a streptozotocinnicotinamide-induced rat model of T2DM [48]. Abroma augusta L. leaf was found to reduce hyperglycemia, hyperlipidemia, membrane disintegration, oxidative stress, and oxidative stress-induced cell death in the kidneys and hearts of the diabetic rats [48]. Phytochemical screening revealed the presence of taraxerol, flavonoids, and phenolic compounds in Abroma augusta L. leaf [48]. Therefore, there's need for further investigation on the specificity and offtarget effects of this natural extract although the doses provided in this study did not produce side effects in the diabetic rats.

Aegle marmelos Leaf Extract (AME): AME was studied in a rat model of alloxan-induced DM for its effect on early stage DCM [49]. The results showed that AME evidently increased the antioxidants GSH, CAT, and SOD and rescued the DMinduced cardiac necrosis and inflammation [49].

Dendrobium officinale Extract (DOE): was shown to elevate the antioxidant SOD and decrease the production of malondialdehyde (MDA), the accumulation of lipid, and the expression of the fibrotic factors TGF- $\beta$, collagen- 1 , and fibronectin, as well as the inflammatory factors NF- $\kappa \mathrm{B}$, tumor necrosis factor alpha, and interleukin-1 beta, in the hearts of STZ induced diabetic mice [50]. DOE at $300 \mathrm{mg} / \mathrm{kg}$ also had a significant inhibitory impact on hyperglycemia and cardiac hypertrophy [50]. The effects of DOE on DCM were evident. However, the severe cardiac remodeling, such as hypertrophy and fibrosis, during the 8-week period of DM [50], needs to be further confirmed in future studies.

Fermented Rooibos Extract (FRE): The protective effect of FRE was evaluated on DCM in a STZ-induced rat model of DM [51]. The results showed that FRE preserved GSH activity in the cardiomyocytes isolated from the diabetic rats and prevented the cells from $\mathrm{H}_{2} \mathrm{O}_{2}$ or an ischemic solutioninduced generation of ROS and apoptosis [51]. This protective effect was more prominent as compared with that of another antioxidant vitamin $\mathrm{E}$ [51].

Ficus racemosa Bark Extract: Possess antioxidant activity, was tested in STZ-induced diabetic rats, for its effect on DCM [52]. The extract was found to enhance the activity of SOD and reduce the level of MDA in the hearts of the diabetic rats [52].

Ginkgo biloba Extract: Fitzl et al, 1999 treated STZ-induced diabetic rats with Ginkgo biloba extract and found that Ginkgo biloba extract could prevent the loss of myofibrils and the reduction of cardiomyocyte diameter [53]. Ginkgo biloba extract was able to increase cardiac SOD activity, without altering the mRNA of inducible nitric oxide synthase [53]. Therefore, the protective effect of this natural product on DCM could be due to its action in scavenging upon DMinduced free radicals, but not blocking the source of ROS.
Kalpaamruthaa: The effect of kalpaamruthaa on DCM was tested in a rat model of T2DM [54]. Kalpaamruthaa was found by Latha et al, (2013) to reduce the expression of NOX and endothelial nitric oxide synthase, the effects of which led to a decrease in DM-induced accumulation of cardiac lipid peroxides, proinflammatory cytokines, matrix metalloproteinase- 2 and matrix metalloproteinase-9, and cardiac remodeling [54]. A subsequent study by the same group showed that kalpaamruthaa inhibited DM-induced cardiac lipid accumulation, chromatin condensation, and marginalization; increased hepatic antioxidants; improved insulin resistance; and lowered blood glucose level [55].

The ability to inhibit PKC- $\beta$ and enhance Akt activity was suggested to account for the protective effect of kalpaamruthaa on DCM [54]. In a following study, the same group further observed that kalpaamruthaa could increase pancreatic antioxidants and reduce pancreatic lipid peroxides and carbonyl content, markers of injury in the plasma, heart, and liver [55]. The decreased cardiac expression of protease-activated receptor-1 by kalpaamruthaa was indicated for the cardiac protection by kalpaamruthaa [56].

These studies addressed the beneficial role of kalpaamruthaa in protection against DCM. It is needed to clarify the mechanism of this natural product, since it is still unclear whether the protection was due to kalpaamruthaa's alteration of DM or was as a result of other mechanisms. Moreover, several factors were suggested to be the key targets of kalpaamruthaa. It would be helpful to elucidate the exact key factor through which kalpaamruthaa exerts the function by using gene silencing or gene knockout models.

North American Ginseng (NAG): NAG (Panax quinquefolius) was studied for its effect on DCM in both STZinduced type 1 diabetic mice and DB/DB spontaneous type 2 diabetic mice [57]. NAG had the capability to reduce the DMinduced expression of cardiac extracellular matrix proteins and vasoactive factors, as well as cardiac hypertrophy and dysfunction in both types of the mice [57]. NAG, the effect of which might mediate NAG's protection against DCM, diminished the DM-induced cardiac oxidative stress [57]. With the diverse phytochemical constituents within NAG, the outcome must be a combination of all the effects exerted by all the constituents. It would be interesting to clarify the key targets of the constituents that may play the major roles in the effect of NAG on DCM. As a result, the most effective constituent and the most potent target could be screened out. This may increase the bioavailability and specificity.

Pongamia pinnata: Its effect on DCM was tested by using STZ/nicotinamide-induced type 2 diabetic rats [58]. Pongamia pinnata decreased blood glucose level, increased the antioxidants SOD and GSH in the hearts of the diabetic mice, and exhibited cardiac protection against DM-induced oxidative damage, biomarkers for cardiac injury, cardiac remodeling, and dysfunction [58]. The exact target of this natural product was not indicated in this study, which needs to be further elucidated in future studies.

Syzygium cumini: Syzygium cumini was evaluated in H9c2 cells for its protection against glucose stress-induced injury and was found to attenuate high glucose-induced cell hypertrophy and accumulation of extracellular matrix [59], which are hallmarks of long-term diabetic complications[60, 27], including DCM [61]

\section{POLYHERBAL FOR DIABETES}

It has been observed that multiple mechanisms in the treatment of diabetes will effectively control the progress as 
well as modify the deteriorating condition of the patients. To obtain multimodal activities in control of diabetes, certain purposeful mixtures of herb have been comprehensively evaluated for their effective uses in patients with diabetes. Such polyherbals are usually target the different pathological events throughout instigation and development of diabetes from different mechanistic approaches, to abolish the symptoms to improve the quality of life of the patient

Composition of polyherbal formulations in the treatment of diabetes mellitus.

\begin{tabular}{|c|c|}
\hline Polyherbals & Botanical composition (part used) \\
\hline GSPF kwath & $\begin{array}{l}\text { Gymnema sylvestre (Retz.) R.Br. (leaves), Syzygium cumini (L.) Skeels (seeds), Phyllanthus emblica L. } \\
\text { (fruit), Curcuma longa L. (rhizome), Pterocarpus marsupium Roxb. (Heart-wood), Terminalia chebula Retz. } \\
\text { (fruit), Cassia fistula L. (fruit), Picrorhiza kurroa Royle ex Benth. (rhizome), Swertia chirata (seeds), } \\
\text { Terminalia bellirica (fruit) }\end{array}$ \\
\hline $\begin{array}{l}\text { Polyherbal } \\
\text { formulation }\end{array}$ & $\begin{array}{l}\text { Ferula assafoetida, Annona squamosal, Zingiber officinale (juice), Gymnema sylvestre (leaves), Tamarindus } \\
\text { indica (seeds), Azadirachta indica, Trigonella foenumgraecum (seeds), Moringa oleifera (roots), Aegle } \\
\text { marmelos (seeds), Cajanus cajan (leaves) }\end{array}$ \\
\hline $\begin{array}{l}\text { Polyherbal } \\
\text { formulation }\end{array}$ & $\begin{array}{l}\text { Salacia roxburghii (root and fruits), Salacia oblonga (root and fruits), Garcinia indica (fruits and seeds), } \\
\text { Lagerstroemia parviflora (bark) }\end{array}$ \\
\hline SMK001 & Coptis chinensis, Trichosanthes kirilowii \\
\hline DIASOL & $\begin{array}{l}\text { Eugenia jambolana, Foenum graecum, Terminalia chebula, Quercus infectoria, Cuminum cyminum, } \\
\text { Taraxacum officinale, Emblica officinalis, Gymnema sylvestre, Phyllanthrus nerui, Enicostemma littorale }\end{array}$ \\
\hline DiaKure & $\begin{array}{l}\text { Vetiveria zizanioides (root), Hemidesmus indicus (rhizome), Strychnos } \\
\text { potatorum (seed), Salacia reticulata (bark), Holarhena antidysenterica (seed), Cassia auriculata (bark), } \\
\text { Trigonella graecum (seed), Acacia catechu (bark) }\end{array}$ \\
\hline DRF/AY/5001 & $\begin{array}{l}\text { Gymnema sylvestre (leaves), Syzygium cuimini (seed), Pterocarpus marsupium (stem), Momordica } \\
\text { charantia (seed), Emblica officinalis (fruit), Terminalia belirica (fruit), Terminalia chebula (fruit), Shudh } \\
\text { Shilajit }\end{array}$ \\
\hline ESF/AY & $\begin{array}{l}\text { Aegle marmelos (leaves), Bambusa arundinacee (leaves), Eruca sativa (leaves), Aerva lanata (aerial), } \\
\text { Catharanthus roseus (aerial), Ficus benghalensis (bark), Salacia reticulate (bark), Syzygium cumini (bark) }\end{array}$ \\
\hline
\end{tabular}

MARKETED HERBAL MEDICATIONS FOR DIABETIC TREATMENT: ITS COMPOSITION

\begin{tabular}{|c|c|}
\hline $\begin{array}{l}\text { Polyherbal } \\
\text { Formulations }\end{array}$ & Ingredients \\
\hline Diabecon[62] & $\begin{array}{l}\text { Sphaeranthus indicus, Tribulus terrestris, Tinospora cordifolia, Triphala, Curcuma longa, Rumex maritimus, Aloe } \\
\text { vera, Swertia chirata, Ocimum sanctum, Gymnema sylvestre, Sphaeranthus indicus, Glycyrrhiza glabra, } \\
\text { Commiphora wightii, Phyllanthus amarus, Boerhavia diffusa, Piper nigrum, Tribulus terrestris, Pterocarpus } \\
\text { marsupium, Syzygium cumini, Tinospora cordifolia, Berberis aristata, Gmelina arborea, Asparagus racemosus, } \\
\text { Abutilon indicum, Casearia esculenta, Berberis aristata, Gossypium herbaceum. }\end{array}$ \\
\hline Glyoherb[63] & $\begin{array}{l}\text { Gudmar (Gymnema sylvestre), Mahamejva, Katuki (Picrorhiza kurrooa), Chirayata (Swertia chirata), Karela } \\
\text { (Momordica charantia), Indrajav (Holarrhena pubescens), Amala (Phyllanthus emblica), Gokshur (Tribulus } \\
\text { terretris), Haritaki (Terminalia chebula), Jambu bij (Eugenia Jambolana), Methi (Trigonella foenum-graecum), } \\
\text { Neem, Chandraprabha, Arogyavardhini, Haridra (Curcuma longa), Bang Bhasma, Devdar, Daruhaldi (Berberis } \\
\text { aristata), Nagarmotha (Cyperus scariosus), Shuddha Shilajit, Galo }\end{array}$ \\
\hline $\begin{array}{l}\text { Diabeta } \\
\text { Plus[64] }\end{array}$ & $\begin{array}{l}\text { Vijayasar (Pterocarpus marsupium), Gurmar (Gymnema sylves), Jamun (Syzygium cumini), Karela (Momordica } \\
\text { charantia), Shilajit (Asphaltum), }\end{array}$ \\
\hline
\end{tabular}

Several research of herbal products for the remedy of diabetes has developed several antidiabetic products in the market worldwide. Few of them include, Diabecon $\AA$, Glyoherb, Diabeta Plus, etc. Diabecon $\AA$ is a product by Himalaya Herbal Healthcare, is one of the well marketed polyherbal formulation in diabetes care [63]. Composion of the formulation has been depicted in table above. Aside from ISSN: 2250-1177 promoting b-cell repair and regeneration, it also protects the $\mathrm{b}$-cells from oxidative stress and increases $\mathrm{C}$-peptide levels. It mimics insulin actions by reducing $\mathrm{HbA1c}$ level, normalizing microalbuminuria and regulating the lipid profile. Diabecon ${ }^{\circledR}$ also possess antioxidant properties and claims to minimize complications in diabetic patients [63]. Diabecon was compared to Hyponidd, Inolter and Cogent DB 
based on their effectiveness in reducing HbA1c [65], where Diabecon $\AA$ showed an increased fasting insulin and $C$ peptide levels compared to the other agents [65].

Similarly, Glyoherb is also a polyherbal antihyperglyceamic formulation that has additional properties of antihyperlipidemic and antioxidant properties. It is marketed to prevent, delay or improve complications such as retinopathy, neuropathy and retinopathy [63]. Results in animal testing suggested that it increases glucose tolerance and lowers blood glucose levels in STZ-induced type 1 diabetic rats [66]. Additionally, treatment with Glyoherb has shown to reduce serum cholesterol, TGs, VLDL, LDL levels compared to control groups but is not as effective as glibenclamide. It had also shown to increase HDL levels [66]. Glyoherb did not exert any toxic effects in STZ-induced impaired kidney and liver functions rather it improved the kidney and liver functions [66]. On the other hand, Diabeta Plus is also an antidiabetic polyherbal formulation that has additional properties of potent immunomodulator, antihyperlipidemic, anti-stress and is hepatoprotective [63]. Use of Diabeta alone works by attacking various factors that can precipitate diabetic condition thus preventing or delaying the complications in pre-diabetics. It helps to decrease resistance when used in conjunction with oral hypoglycaemic agents, claims to relief complaints of pruritus, pain and polyuria caused by diabetes mellitus [63].

\section{CONCLUSIONS}

Natural products with antioxidative properties have been shown to ameliorate diabetes in animal models. Several natural products have been used in clinical trials in patients with DM, even as traditional medicines for the treatment of DM for many years. The ability of these natural products in enhancing serum antioxidative activity and reducing serum oxidative stress may also be beneficial for the amelioration of other associated complications of diabetes. Given the antioxidative and even blood glucose-lowering effects of the natural products, they have a great potential for the future clinical use as alternative medicines for the management of DM and its associated complications. Despite the bright future of the natural products in the treatment of diabetes, a few challenges should be carefully considered before the use of natural products in clinical trials. Natural products have multiple targets. This fact may lead to off-target effects, including both the beneficial and the detrimental. Hence, more selective compounds should be developed. The development of SFN and curcumin, isolated from natural products, is a good example, although the two compounds have multiple targets. An in-depth mechanisms need to be elucidated, the result of which can provide a solid basis for the development of novel high-selective compounds.

In addition, the blood glucose-lowering effect of some natural products is beneficial. However, the question of whether or not natural products lead to unstable blood glucose level in diabetic patients is a concern. Thus, attention should be paid to the fine control of blood glucose level using the combination of standard medicines and natural products as alternative medicines in the treatment of DM or its associated complications.

In summary, natural products with antioxidative profiles in the management of diabetes on one hand have great potentials and face great challenges on the other. The success of natural products in the management of diabetes requires extensive studies on the mechanism, specificity, bioavailability, and drug-to-drug interactions.

\section{REFERENCES}

[1] Bastaki A, Diabetes mellitus and its treatment. International journal of Diabetes and Metabolism, 2005; 13(3):111.

[2] Joseph B, Jini D, Insight into the hypoglycaemic effect of traditional Indian herbs used in the treatment of diabetes. Res J Med Plant, 2011; 5(4): 352-376.

[3] Piero MN, Nzaro GM, Njagi JM, Diabetes mellitus-a devastating metabolic disorder. Asian journal of biomedical and pharmaceutical sciences, 2015; 5(40):1.

[4] Nasar MK, Prevention and management of diabetes and its complications by unani herbal medicine - a review. Endocrinol Metb Int J. 2017; 4 (4):101-105. DOI: 10.15406/emij.2017.04.00094

[5] Khare CP. Indian Medicinal Plants. (1st edn), Springer (India) private limited, India, 2007; pp. 587.

[6] CCRUM. Unani Pharmacopoeia of India. 2007.

[7] Dey L, Attele AS, Yuan CS. Alternative therapies for type 2 diabetes. Altern Med Rev. 2002; 7 (1): 45-58.

[8] Kar A, Choudhary BK, Bandyopadhyay NG, Comparative evaluation of hypoglycaemic activity of some Indian medicinal plants in alloxan diabetic rats. J Ethnopharmacol. 2003; 84(1):105-108.

[9] Karen Sanders, Aloe Vera juice helps lowers blood sugar and cholesterol. Natural Health. 2013; 365(4): 122-127.

[10] Rajnandan Patnaik, International journal of innovative research \& development. 2014; 3(12): 401-407.

[11] Devaraj S, Yimam M, Brownell LA, Jialal I, Singh S, Jia Q, Effects of Aloe vera supplementation in subjects with prediabetes/metabolic syndrome, Metabolic Syndrome and Related Disorders, 2013; 11(1): 35-40.

[12] Mahmoud F, Haines D, Al-Ozairi E, Dashti A, Effect of black tea consumption on intracellular cytokines, regulatory T cells and metabolic biomarkers in type 2 diabetes patients, Phytotherapy Research, 2016; 30(3): 454- 462.

[13] Zemestani M, Rafraf M, Asghari-Jafarabadi M, Chamomile tea improves glycemic indices and antioxidants status in patients with type 2 diabetes mellitus, Nutrition, 2016; 32(1): 66-72.

[14] Kaatabi H, Bamosa AO, Badar A, Al-Elq A, Abou-Hozaifa B, Lebda F, Al-Khadra A, Al-Almaie S, Nigella sativa improves glycemic control and ameliorates oxidative stress in patients with type 2 diabetes mellitus: placebo controlled participant blinded clinical trial, 2015; PLoS One, 10(2): article e0113486.

[15] Fatima N, Pingali U, Muralidhar N, Study of pharmacodynamics interaction of Phyllanthus emblica extract with Clopidogrel and ecosprin in patients with type II diabetes mellitus, Phytomedicine, 2014; 21(5) 579-585.

[16] Ahmad MS, Ahmed N, Antiglycation properties of aged garlic extract: possible role in prevention of diabetic complications, The Journal of Nutrition, 2006; 136(3): 796S-799S.

[17] Shiju TM, Rajesh NG, Viswanathan P, Renoprotective effect of aged garlic extract in streptozotocin-induced diabetic rats, Indian Journal of Pharmacology, 2013; 45(1): 18-23.

[18] Thomson M, Al-Qattan KK, Divya JS, Ali M, Antidiabetic and anti-oxidant potential of aged garlic extract (AGE) in streptozotocin-induced diabetic rats, BMC Complementary and Alternative Medicine, 2016; 16: 17.

[19] Dillon SA, Lowe GM, Billington D, Rahman K, Dietary supplementation with aged garlic extract reduces plasma and urine concentrations of 8-iso-prostaglandin $\mathrm{F}(2$ alpha) in smoking and nonsmoking men and women, The Journal of Nutrition, 2002; 132(2): 168-171.

[20] Weiss N, Ide N, Abahji T, Nill L, Keller C, Hoffmann U, “Aged garlic extract improves homocysteine induced endothelial dysfunction in macro- and microcirculation," The Journal of Nutrition, 2006; 136(3): 750S-754S.

[21] Atkin M, Laight, D, and Cummings MH, The effects of garlic extract upon endothelial function, vascular inflammation, oxidative stress and insulin resistance in adults with type 2 diabetes at high cardiovascular risk. A pilot double blind randomized placebo controlled trial, Journal of Diabetes and its Complications, 2016; 30(4): 723-727.

[22] Qian Q, Qian S, Fan P, Huo D, Wang S, Effect of Salvia miltiorrhiza hydrophilic extract on antioxidant enzymes in diabetic patients with chronic heart disease: a randomized controlled trial, Phytotherapy Research, 2012; 26(1): 60-66. 
[23] Singh R, Kaur N, Kishore L, Gupta GK, Management of diabetic complications: a chemical constituents based approach, Journal of Ethnopharmacology, 2013; 150(1): 51-70.

[24] Bai Y, Cui W, Xin, Y., et al., "Prevention by sulforaphane of diabetic cardiomyopathy is associated with up-regulation of Nrf2 expression and transcription activation," Journal of Molecular and Cellular Cardiology, vol. 57, pp. 82-95, 2013.

[25] Zhang Z, Chen J, Jiang X, Wang J, Yan X, Zheng Y, Conklin DJ, Kim K, Kim KH, Tan Y, Kim YH, Cai L, The magnolia bioactive constituent 4-0-methylhonokiol protects against high-fat dietinduced obesity and systemic insulin resistance in mice, Oxidative Medicine and Cellular Longevity, 2014; Article ID 965954, 10 pages.

[26] Gu J, Cheng Y, Wuet H, al., Metallothionein is downstream of Nrf2 and partially mediates sulforaphane prevention of diabetic cardiomyopathy, Diabetes, 2017; 66(2): 529-542.

[27] Wu H, Kong L, Zhou S, Cui W, Xu F, Luo M, Li X, Tan Y, Miao L, The role of microRNAs in diabetic nephropathy, Journal of Diabetes Research, 2014; Article ID 920134, 12 pages.

[28] Wu H, Kong L, Cheng Y, Zhang Z, Wang Y, Lou M, Tan Y, Chen X, Miao L, Cai L, Metallothionein plays a prominent role in the prevention of diabetic nephropathy by sulforaphane via upregulation of Nrf2, Free Radical Biology \& Medicine, 2015; 89: 431-442.

[29] Bahadoran Z, Tohidi M, Nazeri P, Mehran M, Azizi F, Mirmiran $P$, Effect of broccoli sprouts on insulin resistance in type 2 diabetic patients: a randomized double-blind clinical trial, International Journal of Food Sciences and Nutrition, 2012 63(7): 767-771.

[30] Abo-Salem OM, Harisa GI, Ali TM, El- Sayed e-SM, Abou-Elnour FM, Curcumin ameliorates streptozotocin-induced heart injury in rats, Journal of Biochemical and Molecular Toxicology, 2014; 28(6):263-270.

[31] Yu W, Wu J, Cai F, Xiang J, Zha W, Fan D, Guo S, Ming Z, Liu C, Curcumin alleviates diabetic cardiomyopathy in experimental diabetic rats, PLoS One, 2012; 7(12): article e52013.

[32] Soetikno V, Sari FR, Sukumaran V, Lakshmanan AP, Mito S, Harima M, Thandavarayan RA, Suzuki K, Nagata M, Takagi R, Watanabe $\mathrm{K}$, Curcumin prevents diabetic cardiomyopathy in streptozotocin-induced diabetic rats: possible involvement of PKC-MAPK signaling pathway, European Journal of Pharmaceutical Sciences, 2012; 47(3): 604-614.

[33] Aziz MT, El Ibrashy IN, Mikhailidis DP, Rezq AM, Wassef MA Fouad HH, Ahmed HH, Sabry DA, Shawky HM, Hussein RE, Signaling mechanisms of a water soluble curcumin derivative in experimental type 1 diabetes with cardiomyopathy, Diabetology and Metabolic Syndrome, 2013; 5(1): 13.

[34] Yu W, Zha W, Ke Z, Min Q, Li C, Sun H, Liu C, Curcumin protects neonatal rat cardiomyocytes against high glucose-induced apoptosis via PI3K/Akt signalling pathway, Journal of Diabetes Research, 2016; Article ID 4158591, 11 pages.

[35] Wu H, Kong L, Tan Y, Epstein PN, Zeng J, Gu J, Liang G, Kong M, Chen X, Miao L, Cai L, C66 ameliorates diabetic nephropathy in mice by both upregulating NRF2 function via increase in miR 200a and inhibiting miR-21, Diabetologia, 2016; 59(7): 15581568.

[36] Pan Y, Wang Y, Zhao Y, Peng K, Li W, Wang Y, Zhang J, Zhou S, Liu Q, Li X, Cai L, Liang G, Inhibition of JNK phosphorylation by a novel curcumin analog prevents high glucose induced inflammation and apoptosis in cardiomyocytes and the development of diabetic cardiomyopathy, Diabetes, 2014 63(10): 3497-3511.

[37] Liu Y, Wang Y, Miao X, Zhou S, Tan Y, Liang G, Zheng Y, Liu Q, Sun J, Cai L, Inhibition of JNK by compound C66 prevents pathological changes of the aorta in STZ-induced diabetes, Journal of Cellular and Molecular Medicine,2014; 18(6): 12031212.

[38] Bao $\mathrm{H}$, Chen L, Icariin reduces mitochondrial oxidative stress injury in diabetic rat hearts, Zhongguo Zhong Yao Za Zhi, 2011; 36(11): 1503-1507.

[39] Yu W, Zha W, Guo S, Cheng H, Wu J, Liu C, Flos Puerariae extract prevents myocardial apoptosis via attenuation oxidative stress in streptozotocin-induced diabetic mice, PLoS One, 2014; 9(5): article e98044.

[40] Han J, Tan C, Wang Y, Yang S, Tan D, Betanin reduces the accumulation and cross-links of collagen in high fructose- fed rat heart through inhibiting non-enzymatic glycation, Chemico-Biological Interactions, 2015; 227: 37- 44.
[41] Bi L, Tian X, Dou F, Hong L, Tang H, Wang S, New antioxidant and antiglycation active triterpenoid saponins from the root bark of Aralia taibaiensis, Fitoterapia, 2012; 83(1): 234-240.

[42] Weng Y, Yu L, Cui J, Zhu Y, Guo C, Wei G, Duan J, Yin Y, Guan Y, Wang Y, Yang Z, Xi M, Wen A, Antihyperglycemic, hypolipidemic and antioxidant activities of total saponins extracted from Aralia taibaiensis in experimental type 2 diabetic rats, Journal of Ethnopharmacology, 2014; 152(3): 553-560.

[43] Xi M, Hai C, Tang H, Wen A, Chen H, Liu R, Liang X, Chen M, Antioxidant and antiglycation properties of triterpenoid saponins from Aralia taibaiensis traditionally used for treating diabetes mellitus, Redox Report, 2010; 15(1): 20-28.

[44] Duan J, Wei G, Guo C, Cui J, Yan J, Yin Y, Guan Y, Weng Y, Zhu Y, Wu X, Wang Y, Xi M, Wen A, Aralia taibaiensis protects cardiac myocytes against high glucose-induced oxidative stress and apoptosis, The American Journal of Chinese Medicine, 2015 43(6): 1159-1175

[45] Sun W, Zhang Z, Chen Q, Yin X, Fu Y, Zheng Y, Cai L, Kim KH, Tan Y, Kim YH, Magnolia extract (BL153) protection of heart from lipid accumulation caused cardiac oxidative damage, inflammation, and cell death in high-fat diet fed mice, Oxidative Medicine and Cellular Longevity, 2014; Article ID 205849, 13 pages.

[46] Chang WC, Yu YM, Hsu YM, Wu CH, Yin PL, Chiang SY, Hung JS Inhibitory effect of Magnolia officinalis and lovastatin on aortic oxidative stress and apoptosis in hyperlipidemic rabbits, Journal of Cardiovascular Pharmacology, 2006; 47(3): 463-468.

[47] Zhang Z, Chen J, Zhou S, Wang S, Cai X, Conklin DJ, Kim KS, Kim $\mathrm{KH}$, Tan Y, Zheng Y, Kim YH, Cai L, Magnolia bioactive constituent 4-0-methylhonokiol prevents the impairment of cardiac insulin signaling and the cardiac pathogenesis in highfat diet-induced obese mice, International Journal of Biological Sciences, 2015; 11(8): 879-891.

[48] Khanra R, Dewanjee S, Dua TK, Sahu R, Gangopadhyay M, De Feo V, Zia-UI-Haq M, Abroma augusta L. (Malvaceae) leaf extract attenuates diabetes induced nephropathy and cardiomyopathy via inhibition of oxidative stress and inflammatory response, Journal of Translational Medicine, 2015; 13(6) DOI: 10.1186/s12967-014-0364-1.

[49] Bhatti R, Sharma S, Singh J, Ishar MP, Ameliorative effect of Aegle marmelos leaf extract on early stage alloxaninduced diabetic cardiomyopathy in rats, Pharmaceutical Biology, 2011; 49(11): 1137-1143.

[50] Zhang Z, Zhang D, Dou M, Li Z, Zhang J, Zhao X, Dendrobium officinale Kimura et Migo attenuates diabetic cardiomyopathy through inhibiting oxidative stress, inflammation and fibrosis in streptozotocin-induced mice, Biomedicine \& Pharmacotherapy, 2016; 84: 1350-1358.

[51] Dludla PV, Muller CJ, Louw J, Joubert E, Salie R, Opoku AR, Johnson R, The cardioprotective effect of an aqueous extract of fermented rooibos (Aspalathus linearis) on cultured cardiomyocytes derived 12 Journal of Diabetes Research from diabetic rats, Phytomedicine, 2014; 21(5): 595- 601.

[52] Joshi H, Vaishnav D, Sanghvi G, Rabadia S, Airao V, Sharma T, Parmar S, Sheth N, Ficus recemosa bark extract attenuates diabetic complications and oxidative stress in STZ-induced diabetic rats," Pharmaceutical Biology, 2016; 54(9) 15861595.

[53] Fitzl G, Martin R, Dettmer D, Hermsdorf V, Drews H, Welt K Protective effects of Gingko biloba extract EGb 761 on myocardium of experimentally diabetic rats. I: ultrastructural and biochemical investigation on cardiomyocytes, Experimental and Toxicologic Pathology, 1999; 51(3): 189198.

[54] Latha R, Shanthi P, Sachdanandam, P, Kalpaamruthaa ameliorates myocardial and aortic damage in cardiovascular complications associated with type 2 diabetes mellitus, Canadian Journal of Physiology and Pharmacology, 2013; 91(2): 116-123.

[55] Latha R, Shanthi P, Sachdanandam, P, Kalpaamruthaa modulates oxidative stress in cardiovascular complication associated with type 2 diabetes mellitus through PKC-beta/ Akt signaling, Canadian Journal of Physiology and Pharmacology, 2013; 91(11): 901-912.

[56] Latha R, Shanthi P, Sachdanandam P, Protective role of Kalpaamruthaa in type II diabetes mellitus-induced 
cardiovascular disease through the modulation of protease activated receptor-1, Pharmacognosy Magazine, 2015; 11(1): S209-S216.

[57] Sen S, Chen S, Wu Y, Feng B, Lui EK, Chakrabarti S, Preventive effects of North American ginseng (Panax quinquefolius) on diabetic retinopathy and cardiomyopathy, Phytotherapy Research, 2013; 27(2): 290- 298.

[58] Badole SL, Chaudhari SM, Jangam GB, Kandhare AD, Bodhankar SL, Cardioprotective activity of Pongamia pinnata in streptozotocin-nicotinamide induced diabetic rats, BioMed Research International, 2015; Article ID 403291, 8 pages.

[59] Atale N, Chakraborty M, Mohanty S, Bhattacharya S, Nigam D, Sharma M, Rani V, Cardioprotective role of Syzygium cumini against glucose-induced oxidative stress in H9C2 cardiac myocytes, Cardiovascular Toxicology, 2013, 13(3): 278-289.

[60] Ban CR, Twigg SM, Fibrosis in diabetes complications: pathogenic mechanisms and circulating and urinary markers, Vascular Health and Risk Management, 2008; 4(3): 575-596.

[61] Asbun J, Villarreal FJ, The pathogenesis of myocardial fibrosis in the setting of diabetic cardiomyopathy, Journal of the American College of Cardiology, 2006; 47(4): 693-700.
[62] Modak M, Dixit P, Londhe J, Ghaskadbi S, Paul T, Devasagayam A, Serial review indian herbs and herbal drugs used for the treatment of diabetes, J Clin Biochem Nutr, 2007; 40:163-173.

[63] Maninder Kaur VV, Diabetes and antidiabetic herbal formulations: an alternative to Allopathy, Int J Pharmacogn, 2014; 1(10): 614-626. https://doi.org/10.13040/IJPSR.09758232.

[64] Diabeta Plus - Maintain Good Blood Sugar Level - Natural Herbal Supplements | AyurvedicCure.com.

[65] Sridharan K, Mohan R, Ramaratnam S, Panneerselvam D, Ayurvedic treatments for diabetes mellitus. In: Sridharan K, ed. Cochrane Database of Systematic Reviews. Chichester, UK: John Wiley \& Sons, Ltd; 2011. https://doi.org/10.1002/14651858.CD008288.pub2.

[66] Thakkar NV, Patel JA, Pharmacological evaluation of "Glyoherb": a polyherbal formulation on streptozotocininduced diabetic rats, Int J Diabetes Dev Ctries, 2010; 30(1): 17. 